\title{
Exertional and nocturnal periodic breathing after successful cardiac transplantation. A case report
}

\author{
Ugo Corrà, Fabiana Isabella Gambarin, Marco Gnemmi, Massimo Pistono \\ Division of Cardiology, Istituti Clinici Scientifici Maugeri IRCCS, Rehabilitation Center Veruno, Gattico-Veruno (NO), Italy
}

\begin{abstract}
We present a case report of a heart failure patient who underwent cardiopulmonary exercise testing and sleep screening 12 months before and after heart transplantation (HTx). Severe Cheyne-Stokes respiration (CSR) with central sleep apnoea (CSA) was identified either before and after HTx, while periodic breathing during exercise vanished. We suggest that optimization of
\end{abstract}

Correspondence: Dr. Ugo Corrà, Head of the Exercise Pathophysiology Laboratory, Istituti Clinici Scientifici Maugeri, Veruno Institute, Via per Revislate, 13, 28013, Gattico-Veruno (NO), Italy.

Tel. +39.0322.884711 - Fax: +39.0322.830294.

E-mail: ugo.corra@icsmaugeri.it

Ethics approval and consent to participate: No ethical committee approval was required for this case report by the Department, because this article does not contain any studies with human participants or animals. Informed consent was obtained from the patient included in this study.

Availability of data and materials: All data underlying the findings are fully available.

Consent for publication: The patient gave his written consent to use his personal data for the publication of this case report and any accompanying images.

Contributions: All the authors made a substantive intellectual contribution, performed part of the experiments. All the authors have read and approved the final version of the manuscript and agreed to be accountable for all aspects of the work.

Conflict of interest: The authors declare that they have no competing interests, and all authors confirm accuracy.

Key words: heart transplantation; Cheyne-Stoke respiration; exertional periodic breathing.

Received for publication: 1 January 2021.

Accepted for publication: 15 January 2021.

${ }^{\circ}$ Copyright: the Author(s), 2021

Licensee PAGEPress, Italy

Monaldi Archives for Chest Disease 2021; 91:1757

doi: 10.4081/monaldi.2021.1757

This article is distributed under the terms of the Creative Commons Attribution Noncommercial License (by-nc 4.0) which permits any noncommercial use, distribution, and reproduction in any medium, provided the original author(s) and source are credited. hemodynamics and medical therapy (low dose of diuretic) did not withdraw the central mechanisms underlying the diathesis for CSR-CSA. While periodic breathing during exercise reversal may support a closer link with an exertional central hemodynamic. This observation indirectly neglects the possible unifying mechanistic background of CSR and periodic breathing, during exercise, in this setting.

\section{Introduction}

Heart transplantation (HTx) has been a life-saving and lifeextending intervention for end-stage heart failure patients since the 1980s [1]. Periodic breathing disorders (PBD) might be uncovered at rest, during exercise and overnight in heart failure, due to left ventricular dysfunction (HFrEF). Although sleep CheyneStokes respiration (CSR) with central sleep apnoea (CSA) and exertional periodic breathing (EOV) are independently linked to mortality [2], when EOV is associated to CSR-CSA has a particular worst outcome connate [3].

CSR and EOV are uncommon if left ventricular ejection fraction (LVEF) is above 40: causes of CRS-CSA may be prolonged circulation time, pulmonary congestion with diminished pulmonary gas stores, or consecutive "underdamping" of breathing control, or a combination of these [4]. Increased respiratory drive as well as changed chemosensitivity of chemoreceptors are main factors, too.

We describe a case report on the effect of successful HTx on both PBD, daily (during exercise) and nocturnal.

\section{Case Report}

R.S. is a male and he was born in October 1941. An ischaemic cardiomyopathy was diagnosed in 1999 and at the age of 60 years, a triple vessel myocardial revascularization was undertaken. In 2006, he was on optimal pharmacological therapy, in NYHA class II, free of angina pectoris. Ambulatory sleep screening (SS) study and cardiopulmonary exercise testing (CPET) were completed, as described elsewhere [3]. Chest X-ray was defined as normal. EOV and CSR-CSA were identified.

CSA was defined as cessation of airflow lasting at least 10 seconds, in absence of flow and thoraco-abdominal movements while hypopnea was defined as $\geq 50 \%$ decrease in the sum of thoraco-abdominal movements lasting $\geq 10$ seconds, followed by a reduction in oxygen blood saturation $\left(\mathrm{SaO}_{2}\right)$ of at least $4 \%$; CSR was defined as periodic waxing and waning of the depth of respiration with regularly recurring periods of apnoea or hypopnea [2]. 
EOV was visually determined by cyclic fluctuations in minute ventilation, lasting more than $66 \%$ of the exercise duration and with an amplitude of more than $15 \%$ of the average amplitude of cyclic fluctuations at rest [5]

In 2007, he complained intractable muscle fatigue and breathlessness in NYHA Class III-IV: the clinical course was further deteriorated by repeated sustained ventricular beats occurrences. On August $13^{\text {th }}, 2007$, he underwent an orthotropic HTx. In October 2008, the patient was in NYHA class I, on cyclosporine, mycophenolate mofetil, furosemide (12.5 mgr, daily), enalapril (10 mg daily), aspirin, atorvastatin. After HTx, CPET and SS were repeated with the same modality, as before: data are reported in Table 1. EOV disappeared while CSR-CSA was confirmed after HTx, although circulatory and cycle length were (marginally) reduced. Chest radiography was normal. In 2010, CSR-CSA was still preserved, and it was corrected with Auto-Titrating Positive Airway Pressure (At-PAP) treatment.
After almost 10 years (2019), the patient is still alive. He had asymptomatic HFrEF: he underwent myocardial revascularization with angioplasty of interventricular anterior vessel on 2015, November $6^{\text {th }}$, and of right coronary on 2017 , February $10^{\text {th }}$.

The recipient suffered diabetes mellitus not insulin-dependent, that can confuse the clinical scenario of vasculopathy graft.

\section{Discussion}

Few experiences had evaluated PBD before and after HTx. This case report confirms that EOV is sensible to HTx [5], highlighting a relationship between the degree of hemodynamic improvement: none of the recipients had EOV during exercise [7], when Kremser's criteria are assumed [4]. Improvement of cardiac function by HTx might abolish CSR [4,8-9]; most of the patients

Table 1. Clinical, spiroergometric and sleep characteristics of the heart failure patient's (1-year) pre- and post-heart transplantation (HTx).

\begin{tabular}{|c|c|c|}
\hline & Pre-HTx & Post-HTx \\
\hline Age (years) & 61 & 62 \\
\hline Body mass index $\left(\mathrm{kg} / \mathrm{m}^{2}\right)$ & 24.6 & 26.6 \\
\hline NYHA functional class (I-IV) & III & I \\
\hline \multicolumn{3}{|l|}{ Echocardiographic evaluation } \\
\hline Left ventricular ejection fraction (\%) & 22 & 61 \\
\hline \multicolumn{3}{|l|}{ Serum chemistry } \\
\hline Creatinine (mg/dl) & 1.20 & 1.29 \\
\hline Urea $(\mathrm{g} r /)$ & 0.57 & 0.69 \\
\hline \multicolumn{3}{|l|}{ Arterial blood sample } \\
\hline $\mathrm{PaCO}_{2}(\mathrm{mmHg})$ & 31.6 & 27.7 \\
\hline $\mathrm{PaO}_{2}(\mathrm{mmHg})$ & 83.3 & 89.2 \\
\hline $\mathrm{HCO}_{3}(\mathrm{mmol} / \mathrm{l})$ & 23.3 & 18.3 \\
\hline Base excess (mmol/l) & 1.1 & -7.5 \\
\hline $\mathrm{SaO}_{2}(\%)$ & 97.6 & 96.7 \\
\hline \multicolumn{3}{|l|}{ Cardiopulmonary exercise test } \\
\hline Peak workload (watts) & 80 & 100 \\
\hline Peak $\mathrm{VO}_{2}(\mathrm{ml} / \mathrm{kg} / \mathrm{min})$ & 12.5 & 18.0 \\
\hline Percent predicted peak $\mathrm{VO}_{2}(\%)$ & 57 & 68 \\
\hline Peak RER & 1.15 & 1.12 \\
\hline VENCO ${ }_{2}$ slope & 39 & 32 \\
\hline EOV (yes/no) & yes & no \\
\hline \multicolumn{3}{|l|}{ Polysomnography } \\
\hline TST (minutes) & 424 & 402 \\
\hline Total AHI (n/hour) & 40.7 & 40.2 \\
\hline AHI in supine position (n/hour) & 43.3 & 39.4 \\
\hline ODI (n/hour) & 28.6 & 26.8 \\
\hline Percentage of duration of $\mathrm{SaO}_{2}<90 \%(\%)$ & 10 & 4 \\
\hline Minimum $\mathrm{SaO}_{2}(\%)$ & 86 & 80 \\
\hline Circulatory length (seconds) & 60 & 40 \\
\hline Cycle length (seconds) & 180 & 120 \\
\hline
\end{tabular}


suffering from pre-existing CSR will normalize their breathing pattern disorder, however, some recipients continue to show periodic breathing. Although a remarkable progress has been made, including changes in surgical techniques, immunosuppression therapy, donor and recipient selection, and post-transplant care, we showed that apnoea-hypopnea index (AHI) was almost unchanged (Table 1), while a reduction in both the circulatory and cycle length was observed, after successful HTx. The association of EOV and CSR [3], implicitly indicating a common mechanistic background in HFrEF, is largely a matter of speculation.

In HFrEF, beside periodic fluctuations in cardiac output, that directly affect chemoreflex regulation by introducing variations in gas exchange and circulatory delays, ventilatory instability and variability contribute to CSR-CSA development and perpetuation: furthermore, the instability of the respiratory control system arise either from feedback instability due large differences in hypercapnic and hypoxic chemosensitivities across individuals, or from external non-respiratory influences [10]. CSR-CSA persistence might be related to a complex interplay between different pathogenetic contributors, after HTx; both an increased central controller gain and/or baseline hypocapnia may mask the effect of optimization of heart function.

EOV turnaround is unclear, after HTx, as well. EOV is related to a lower $\mathrm{pCO} 2$ at rest, a greater chemosensitivity to $\mathrm{CO}_{2}$, a higher left ventricular filling pressure and pulmonary venous pressure and a prolonged lung to chemoreceptor circulatory delay. Although invasive hemodynamic evaluation was not performed, EOV overturn underscores that an enhanced exertional hemodynamic might play a foremost role.

We cannot exclude that CSR-CSA might be associated to worst outcome, even if this patient lived long after HTx, and also because he responded well at non-invasive respiratory device (At-PAP).

\section{Conclusions}

This case report debates about a HFrEF patient who underwent HTx. Severe CSR-CSA was identified either before and after HTx, while EOV vanished. These data suggest that optimization of hemodynamics and of medical therapy does not withdraw the mechanisms, underlying the diathesis for CSR-CSA. While EOV reversal may support a closer link with an exertional central hemodynamic.

\section{References}

1. Braith RW, Edwards DG. Exercise following heart transplantation. Sports Med 2000;30:171-92.

2. Berry RB, Budhiraja R, Gottlieb DJ, et al. Rules for scoring respiratory events in sleep: update of the 2007 AASM Manual for the Scoring of Sleep and Associated Events. Deliberations of the Sleep Apnea Definitions Task Force of the American Academy of Sleep Medicine. J Clin Sleep Med 2015;8:597-619.

3. Corrà U, Pistono M, Mezzani A, et al. Sleep and exertional periodic breathing in chronic heart failure: prognostic importance and interdependence. Circulation 2006;113:44-50.

4. Braver HM, Brandes WC, Kubiet MA, et al. Effect of cardiac transplantation on Cheyne-Stokes respiration occurring during sleep. Am J Cardiol 1995;76:632-4.

5. Kremser CB, O'Toole MF, Leff AR. Oscillatory hyperventilation in severe congestive heart failure secondary to idiopathic dilated cardiomyopathy or to ischemic cardiomyopathy. Am J Cardiol 1987;59:900-5.

6. Ribeiro JP, Knutzen A, Rocco MB, et al. Periodic breathing during exercise in severe heart failure. Reversal with milrinone or cardiac transplantation. Chest 1987;92:555-56.

7. Corrà U, Piepoli M, Giordano A. Difference in prevalence of exertional oscillatory between healthy subjects and patients with cardiovascular disease. Monaldi Arch Chest Disease 2020;90:1203.

8. Mansfield DR, Solin P, Roebuck T, et al. The effect of successful heart transplant treatment of heart failure on central sleep apnea. Chest 2003;124:1675-81.

9. Thalhofer SA, Kiwus U, Dorow P. Influence of orthotopic heart transplantation on breathing pattern disorders in patients with dilated cardiomyopathy. Sleep Breath 2000;4:121-5.

10. Khoo MCK. Determinants of ventilatory instability and variability. Respir Physiol 2000;122:167-82. 